\title{
LA SUBORDINACIÓN COMO ELEMENTO NECESARIO PARA ACREDITAR LA EXISTENCIA DE UN CONTRATO LABORAL ENTRE LOS TRABAJADORES Y EL SECTOR PÚBLICO CUANDO LA VINCULACIÓN INICIAL ASUME LA FORMA DEL “CONTRATISTA".
}

Subordination as a necessary element to prove the existence of an employment contract between workers and the public sector when the initial relationship assumes the form of the "contractor"

Luz Karime Agamez Agamez ${ }^{1}$

Recibido: 05 de octubre 2019 - Aceptado: 10 de diciembre de 2019

\section{RESUMEN}

Se analiza en este trabajo como la subordinación es el elemento fundamental para acreditar la existencia de los contratos laborales de los trabajadores del sector público o trabajadores oficiales. Se muestran grosso modo las características del postulado constitucional de la primacía de la realidad y cómo la subordinación es la piedra angular de la misma, puesto que, sin la demostración de esta, no podrá predicarse la existencia de un contrato. Se critica la vinculación laboral, a través de contratos de prestación de servicios con los entes del sector público, de quiénes realmente son trabajadores oficiales. En estas circunstancias, la teoría de la primacía de la realidad y los presupuestos para la existencia de la subordinación, operan igual que en las otras modalidades de contratación laboral. La única diferencia, en estos casos, es que el empleador es, precisamente, el Estado; lo que supone una violación sistemática, por parte del Estado Social de Derecho, de los derechos de los asociados.

Palabras clave: Subordinación; Contrato de trabajo; Contrato de Prestación de Servicios; trabajadores oficiales; Contratista; Primacía de la Realidad.

\footnotetext{
${ }^{1}$ Abogada Universidad de Cartagena, Especialista en derecho Administrativo - Laboral Universidad Externado de Colombia. Oficial Mayor Juzgado 14 Administrativo del Circuito de Cartagena. Orcid: https://orcid.org/0000-0002-4897-6139 E-mail: luzkaryme agamez@hotmail.com
} 


\begin{abstract}
It is analyzed in this work how subordination is the fundamental element to prove the existence of labor contracts for public sector workers or official workers. The characteristics of the constitutional postulate of the primacy of reality and how subordination is the cornerstone of it are roughly shown, since, without the demonstration of this, the existence of a contract cannot be acknowledged. The labor relationship, through service provision contracts with public sector entities, of who really are official workers is criticized. In these circumstances, the theory of the primacy of reality and the presuppositions for the existence of subordination operate in the same way as in the other forms of labor contracting. The only difference, in these cases, is that the employer is, precisely, the State; what supposes a systematic violation, on the part of the Welfare State, of the rights of the associates.
\end{abstract}

Keywords: Subordination; Contract of work; Services Provision Contract; Official Workers; Contractor; Primacy of Reality.

\title{
INTRODUCCIÓN
}

A pesar de la abundante jurisprudencia de las altas Cortes, a diario vemos dificultades para establecer la distinción entre trabajadores oficiales y empleados públicos, pues, aunque es conocido que tienen regímenes diferentes, es común llegar a una empresa o entidad estatal y encontrar esa mixtura. En las últimas décadas se ha presentado un fenómeno cada vez más evidente en estas empresas como es la politización de estas y con ello gran parte del personal termina siendo vinculado a través de contratos de prestación de servicios. Es así como la única forma de establecer el verdadero vínculo de estos trabajadores resulta ser la determinación de si existió o no subordinación, entendida como una facultad del empleador “(...) para exigirle el cumplimiento de órdenes al trabajador, en cualquier momento, en cuanto al modo, tiempo o cantidad de trabajo, e imponerle reglamentos, la cual debe mantenerse por todo el tiempo de duración del contrato. Todo ello sin que afecte el honor, la dignidad y los derechos mínimos del trabajador en concordancia con los tratados o convenios internacionales que sobre derechos humanos relativos a la materia obliguen al país” (Código Sustantivo del Trabajo, 1951, Art. 2 literal b).

Se presenta como inquietud: ¿Qué tan respetados son los derechos de los trabajadores del sector oficial?; como quiera que han sido vinculados por medio de contratos de prestación de servicio, cuando en realidad, en razón a la subordinación son trabajadores oficiales y no contratistas; esto como una expresión del abuso del poder respecto a los derechos laborales de rango constitucional. A raíz de lo anterior se plantea como problema jurídico: ¿Cómo se determina la subordinación en la ejecución de la labor de contratistas del estado, para 
Luz Karime Agamez Agamez

efectos de tipificar o establecer la existencia de un contrato de trabajo, en virtud del principio de primacía de la realidad?

Como objetivo general del presente trabajo, se propone la identificación de las características de la subordinación como elemento esencial en la relación laboral de los trabajadores oficiales, pues sin esta como elemento, no puede declararse la existencia de un contrato realidad, en los términos de la jurisprudencia. Para cumplir con dicho objetivo, en específico se hace una revisión conceptual del Código Sustantivo del Trabajo, en particular, los artículos 22, 23 y 24; algunos decretos en los que se puntualiza la naturaleza jurídica de las relaciones laborales de los trabajadores oficiales, y la jurisprudencia de la Corte Suprema de Justicia y la Corte Constitucional. Por último, complementamos la información recogida con algunos textos doctrinarios al respecto que permiten establecer el estado del arte en torno al problema jurídico planteado, para finalmente presentar en este informe los contenidos relevantes y los resultados obtenidos.

Se justifica la presente investigación en atención a que es relevante socialmente, por cuanto, a partir de los resultados obtenidos, se establecen unos parámetros que ayudan a esclarecer lo que en realidad ocurre con los contratos de prestación de servicio que en realidad son contratos de trabajo en la medida en que se prueba la subordinación, y de este modo se propone una mejor comprensión de la contratación en las empresas del estado colombiano, donde hay trabajadores oficiales.

\section{Naturaleza jurídica de los contratos laborales de trabajadores oficiales}

Contrario a lo que ocurre con los empleados públicos, la vinculación de los trabajadores oficiales siempre será a través de un contrato de trabajo, de allí que, a pesar de prestar sus servicios a entidades públicas, se les aplique el Código Sustantivo de Trabajo (1951) en lo que se refiere al derecho laboral individual; no obstante sus contratos de trabajo no se rigen por el mencionado estatuto, sino por las normas especiales como la Ley 6ta (1945) y el Decreto 2127 (1945), las cláusulas del respectivo contrato y la convención colectiva de trabajo, si la hubiere. Estos, de acuerdo a la definición legal contenida en el Decreto 1848 (1969), corresponden al grupo de personas que laboran en los Ministerios, en los Establecimientos Públicos, en las Superintendencias, en los Departamentos administrativos y sus equivalentes en el ámbito territorial o distrital, en la construcción y sostenimiento de las obras públicas, y además quienes prestan sus servicios en las empresas industriales y comerciales del estado de cualquier nivel y sin que importe las funciones asignadas al respectivo organismo, salvo aquellos que desempeñen labores de dirección y confianza, quienes por regla general son empleados públicos.

Los cargos de trabajador oficial son los señalados en la ley para ser desempeñados por personas naturales, vinculadas mediante una relación contractual, regulado por 
disposiciones especiales. Esta categoría especial de servidores públicos, tiene la misma denominación de sus empleos: trabajadores oficiales. El trabajador oficial desempeña entonces una labor que debe encontrarse incorporada en las respectivas plantas de personal. Se han señalado tres criterios para identificar estos empleos: 1. Criterio Orgánico: Tiene en cuenta la naturaleza jurídica de la entidad u organismo estatal y el carácter de adscripción o vinculación a un organismo. 2. Criterio Funcional: Se fundamenta en la naturaleza de las actividades o funciones específicas asignadas al empleo. Y 3. Complementario: es la posibilidad de los establecimientos públicos de determinar, a través de sus estatutos internos, las labores que serían adelantadas por trabajadores oficiales.

Por su naturaleza, en los entes territoriales, ministerios, entidades descentralizadas predomina el empleado público, es decir empleados en carrera administrativa, de libre nombramiento y remoción o de elección popular, y al mismo tiempo se encuentran muy pocos trabajadores oficiales, desempeñando estos últimos las actividades de obra y mantenimiento. Contrario sensu, por regla general, son trabajadores oficiales quienes laboran en las empresas industriales y comerciales del Estado, del nivel nacional y territorial, y en las sociedades de economía mixta con predominio del capital oficial que la jurisprudencia ha definido como superior al $90 \%$.

Sin embargo, es muy común encontrar que en las empresas industriales y comerciales del Estado y, en las sociedades de economía mixta con predominio del capital oficial, va en aumento la vinculación a través del contrato de prestación de Servicios, más conocido en el argot popular como Orden de Prestación de servicios (OPS), esta forma contractual está regulada por las disposiciones del Código Civil (Ley 84, 1873), el Código de Comercio (decreto 410, 1971) o la Ley 80 (1993) según sea el caso, pero en todo caso esta relación es de tipo civil-comercial y no laboral, con todo lo que ello implica.

El problema, es que se ha vuelto recurrente que la vinculación por OPS sea en realidad una relación laboral, pues le exigen al "contratista" el cumplimiento de un horario y una serie de tareas a realizar que quizás no se encuentren expresamente señalados en el contrato, por lo que se presenta una verdadera subordinación al tenor del literal b) del art. 23 del CST, lo que sin lugar a dudas es una relación laboral, disfraza como contrato de Prestación de Servicios para no pagar prestaciones sociales y no cubrir lo que le corresponde al empleador en seguridad social y parafiscales. Esos casos suelen terminar en demandas laborales para la declaración de la existencia de un contrato realidad y el pago de las prestaciones sociales dejadas de cancelar e indemnizaciones por despido injusto; y de esta forma el estado termina pagando más de lo que hubiera cancelado en una relación laboral con contrato de trabajo desde el inicio de la contratación.

${ }^{2}$ Mal llamado contratista, porque en realidad es un trabajador oficial. 
Luz Karime Agamez Agamez

Visto lo anterior, corresponde estudiar como la subordinación es el elemento clave para determinar la existencia de un contrato de trabajo, que inicio como CPS.

\section{La subordinación como elemento diferenciador entre el contrato de trabajo y el contrato de prestación de servicios.}

Lo primero que se debe advertir es que la definición normativa de la Subordinación Laboral se encuentra en el precitado artículo $23^{\circ}$ del CST que consagra expresamente que la subordinación o dependencia es uno de le elementos del contrato de trabajo, al lado de la prestación personal del servicio y de la remuneración periódica o salario.

$\mathrm{Al}$ analizar las características de un contrato de prestación de servicios frente a un contrato laboral, encontraremos que en los dos se encuentran elementos comunes, como la prestación personal del servicio en la que claramente, en ambos casos se refiere a la actividad humana del contratado en la ejecución de un servicio específico; en relación a la remuneración; se encuentran unas leves diferencias ya que en el primero (OPS) corresponde a la contraprestación económica pactada y en el segundo (Contrato de Trabajo) al salario; al observarse este punto es fácil entender grandes similitudes, por ejemplo la forma de pago de la contraprestación económica del contrato de prestación de servicio en estos casos es mensual, es decir, se divide el total del valor del contrato entre el número de meses, lo que a la postre termina siendo como una especie de salario. Es la subordinación el punto diferenciador entre estas dos formas de vinculación, pues si este se encuentra presente definitivamente habrá de declararse la existencia de un contrato de trabajo, aunque se haya pactado como prestación de servicios.

La Corte constitucional enuncia las reglas constitucionales en las que debe estar enmarcada la subordinación como elemento en el contrato de trabajo. Según la jurisprudencia constitucional desde sus inicios ha entendido que “(...) El concepto de subordinación, como sinónimo de sujeción a un sistema jerarquizado de expresión de órdenes, en principio concuerda más bien con el fundamento y razón de ser del contrato de trabajo. Y, aún allí, en el campo del derecho laboral, se admite la existencia de servicios personales -como, por ejemplo, las asesorías prestadas por abogados o contadores independientes-, claramente tipificables fuera del ámbito del Código Sustantivo del Trabajo." (Sentencia T003, 1994) igualmente en sentencia T-161 (1993), en relación con la subordinación y su rango constitucional se estableció que "La subordinación laboral, le da al principio de igualdad una fisonomía distinta, toda vez, que la posición de igualdad existe en el acto de contratación del trabajador, por lo menos desde el punto de vista jurídico, pero desaparece, durante el desarrollo del contrato, en que la subordinación del trabajador al patrono se pone en operación por la necesidad de lograr los objetivos del contrato. La subordinación implica, además, una limitación a la autonomía del trabajador, dado que el 
contrato otorga al patrono la potestad de dirigir la actividad laboral del trabajador, en aras de lograr el mejor rendimiento de la producción, en beneficio de la empresa. Tales limitaciones a los derechos de autonomía e igualdad, si bien son constitucionales, legítimas y justificables, encuentran en el precepto del numeral 4 o del artículo 42 del decreto 2591 (1991), un mecanismo idóneo para evitar abusos, que se generarían en el desconocimiento de dichos derechos."

Mas recientemente la Corte Constitucional en sentencia C-517 (2017) estableció claramente "(...) el elemento distintivo entre las formas contractuales laborales y las civiles o comerciales es el de la subordinación. Así, el trabajador dependiente se encuentra subordinado respecto del empleador, lo cual implica por ejemplo que el primero está sujeto a los horarios y a las órdenes fijadas por el segundo. En cambio, desde el punto de vista de los contratos civiles y comerciales, el trabajador independiente cuenta con libertad y autonomía para ejercer sus labores, por lo que simplemente está obligado a la ejecución del objeto contractual dentro del plazo fijado, según las estipulaciones acordadas."

Es así como, la jurisprudencia constitucional ha establecido ya más que reiteradamente la importancia de la subordinación, como elemento a probar para la declaración de la existencia de un contrato realidad.

\section{Precisiones jurisprudenciales en relación con la subordinación en los contratos laborales de trabajadores oficiales.}

En el artículo $5^{\circ}$ del Decreto 3135 (1968) quedó consagrado que en los estatutos de las empresas se habrían de precisar qué actividades podían ser evacuadas por personal vinculado mediante contrato de trabajo, dicha facultad fue interpretada por la jurisprudencia de las altas cortes y la doctrina nacional como una concesión que la reforma del año de 1968 hizo a los establecimientos públicos, a fin de que estos pudieran modernizarse y adaptarse a las exigencias del servicio público, sin necesidad de provocar una actuación del legislador contraria a la filosofía de eficiencia, eficacia, racionalidad y celeridad que impulsó una gran reestructuración administrativa preconstitucional. En este orden, al criterio orgánico, referido a la naturaleza de la entidad, y al funcional, relacionado con las actividades que en concreto desarrolla el trabajador, se le agregó un tercero complementario, consistente en la posibilidad de los establecimientos públicos de determinar, a través de sus estatutos internos, las labores que serían adelantadas por trabajadores oficiales.

Desde hace mucho la Corte Suprema de Justicia ha establecido una doctrina probable solida en relación con esta materia. Por ejemplo, en sentencia CSJ SL 5971, 16 oct. 1981, esta Sala de la Corte sostuvo que el artículo 5 del Decreto 3135 (1968) "establece que los 
Luz Karime Agamez Agamez

empleados al servicio de los establecimientos públicos son empleados públicos, a menos que sean trabajadores de la construcción y sostenimiento de obras públicas o que, según los estatutos de cada organismo, cumplan actividades que puedan ser desempeñadas por personas vinculadas por contrato de trabajo”.

En igual dirección, en fallo CSJ SL 368 (1987), expresó que las personas que laboran en los establecimientos públicos "se consideran, en principio, empleados públicos conforme lo dispone el artículo $5^{\circ}$ del Decreto 3135 de 1968, con excepción de los trabajadores de la construcción y sostenimiento de obras públicas que son trabajadores oficiales, así como también aquellos cuyas actividades estén precisadas en los respectivos estatutos como susceptibles de ser desempeñadas por personas vinculadas mediante contrato de trabajo".

No hay que olvidar que años después, la Corte Constitucional, en sentencia C-484 (1995), C-493 (1996) y C-536 (1996), consideró que, a diferencia de la potestad concedida a las empresas industriales y comerciales del estado de precisar en sus estatutos internos las actividades de dirección o confianza que debían ser desempeñadas por empleados públicos, la delegación legislativa entregada a los establecimientos públicos para establecer las actividades que serían realizadas por trabajadores oficiales era incompatible con el nuevo régimen constitucional, puesto que la atribución de clasificar los servidores públicos era exclusiva del Congreso, la Asamblea Departamental o el Consejo Municipal.

Es decir, en tratándose de las empresas industriales y comerciales del Estado dicha facultad era una genuina precisión o reglamentación de orden administrativo, en tanto se encontraba circunscrita y subordinada a que se ejerciera respecto a labores que comportaran funciones de confianza o dirección; en contraposición a la que ejercían libremente los establecimientos públicos y sin que estrictamente estuviera supeditada a la construcción y sostenimiento de obras públicas.

Observamos entonces que la subordinación jurisprudencialmente se convierte en la piedra angular de los procesos de declaración de existencia de contrato realidad, máxime cuando se trata de trabajadores oficiales, que como vemos son por lo general trabajadores que cotidianamente se dedican a la ejecución de una o varias labores. Por ejemplo resultaría difícil lograr establecer que el señor que hace periódicamente el mantenimiento a los aires acondicionados de una dependencia del SENA, es un trabajador oficial, aunque su contrato sea de prestación de servicios; tendría que probarse en el proceso que el señor cumplía determinado horario, que su labor se encontraba sujeta a las órdenes directas del director de mantenimiento de esa empresa y de vez en cuando también hacia otras labores que a pesar de no estar expresamente señaladas en su contrato, las realizaba por la intrínseca convicción de la existencia de una subordinación a su superior. 
La jurisprudencia de la corte constitucional ha venido sosteniendo que como quiera que estamos en un Estado social y democrático de derecho, donde la principal inspiración del Estado es la protección a los derechos constitucionales fundamentales y el respeto por la dignidad humana, para dicha corporación no es concebible que, mediante la subordinación, como poder que tiene el empleador, se comentan actos atentatorios de tales derechos. Es así como mediante sentencia C-934 (2004), sostuvo la corte constitucional que: “(...) Dentro del elemento subordinación se destaca, como ya lo ha sostenido la jurisprudencia, el poder de dirección en la actividad laboral y la potestad disciplinaria que el empleador ejerce sobre sus trabajadores para mantener el orden y la disciplina en su empresa. Esa facultad, como es obvio, se predica solamente respecto de la actividad laboral y gira en torno a los efectos propios de esa relación laboral. Sin embargo, aun en ese ámbito de trabajo la subordinación no puede ni debe ser considerada como un poder absoluto y arbitrario del empleador frente a los trabajadores. En efecto, la subordinación no es sinónimo de terca obediencia o de esclavitud toda vez que el trabajador es una persona capaz de discernir, de razonar, y como tal no está obligado a cumplir órdenes que atenten contra su dignidad, su integridad o que lo induzcan a cometer hechos punibles. El propio legislador precisó que la facultad que se desprende del elemento subordinación para el empleador no puede afectar el honor, la dignidad ni los derechos de los trabajadores y menos puede desconocer lo dispuesto en tratados o convenios internacionales que sobre derechos humanos relativos a la materia obliguen a Colombia (...)". En dicha sentencia se destacó además que: “(...) una de las expresiones de esa subordinación o dependencia del trabajador respecto del empleador es el poder de dirección que conlleva a la facultad de impartir órdenes, de establecer las directrices que han de guiar la actividad laboral y por supuesto la de imponer un reglamento interno que contenga las normas no sólo de comportamiento dentro de ella sino las disposiciones reguladoras de la actuación de ambas partes de la relación laboral. Dicho reglamento regirá las políticas de la empresa, las relaciones laborales y regulará las condiciones en que debe desarrollarse el trabajo. Este ha sido definido como "el conjunto de normas que determinan las condiciones a que deben sujetarse el patrono y sus trabajadores en la prestación del servicio”.

Mediante Sentencia C-1110 (2001), la corte constitucional sostuvo que: “(...) Cuando se hace énfasis en la subordinación jurídica no se está negando que en las relaciones laborales exista también subordinación económica, que es aquella que generalmente se presenta cuando una persona depende de otra en las fuentes de subsistencia. De hecho, el trabajador, al igual que todas las personas con deficiente capacidad económica, se encuentra subordinado económicamente a otra, en el caso particular a su empleador quien, por lo general, tiene bajo su dirección la unidad de explotación económica donde el trabajador presta sus servicios personales. En este sentido, también es notoria la desigualdad fáctica entre trabajadores y empleadores, puesto que la explotación 
Luz Karime Agamez Agamez

económica que constituye el soporte del concepto de empresa no existe en abstracto sino como un conjunto de factores que está bajo la dirección de un empresario-empleador que se beneficia de la colaboración de sus subordinados pagando a cambio un salario proporcional a la cantidad y a la calidad del trabajo realizado."

En virtud de la subordinación jurídica laboral, el empleador está autorizado para exigir el cumplimiento de órdenes en cualquier momento, respecto al modo, tiempo o cantidad de trabajo e imponer reglamentos internos de trabajo "todo ello sin que afecte el honor, la dignidad y los derechos mínimos del trabajador en concordancia con los tratados o convenios internacionales que sobre derechos humanos relativos a la materia obliguen al país". Cabe observar, que esta subordinación o dependencia debe ser continuada, en tanto que pueda ejercerse por el empleador en cualquier momento y mientras dure el contrato. Por este motivo el artículo 23 literal b) del CST prescribe que dicha subordinación "debe mantenerse por todo el tiempo de duración del contrato".

Frente a tal subordinación con trabajadores oficiales, la corte constitucional ha sostenido en sentencia T - 426 (2015) que: “(...)” Para la Corte la vinculación a la administración pública puede efectuarse mediante (i) un vínculo reglamentario o contractual de los cuales surge una relación laboral que origina prestaciones sociales o (ii) mediante un contrato de prestación de servicios del cual derivan no derivan derechos prestacionales ni beneficios de tipo labora. Sin embargo, de acuerdo a la jurisprudencia de esta Corporación es posible que de facto el contrato de prestación de servicios cambie su naturaleza hacia un vínculo de carácter laboral, cuando se acreditan materialmente la prestación personal, continuada, subordinada y remunerada de un servicio." Es decir, cuando se encuentre probada la subordinación.

\section{Elementos para determinar la existencia de la subordinación.}

Como se ha observado desde el punto de vista jurisprudencial el elemento diferenciador entre el contrato de trabajo y el contrato de prestación de servicios es la Subordinación, por ello el artículo 24 del Código Sustantivo del Trabajo (1951) dispone que toda relación de trabajo personal, refiriéndose a la que cumpla con los tres requisitos antes analizados, se presume regida por un contrato de trabajo; de allí que se ha establecido como regla probatoria en procesos judiciales de declaración de existencia de contrato realidad, que el demandante que es el trabajador deba demostrar la ejecución personal de un servicio para que se presuma en su favor la existencia de un vínculo laboral.

La Ley 80 (1993), en su artículo 32, define dichos contratos, de la siguiente forma: “3. Son contratos de prestación de servicios los que celebren las entidades estatales para desarrollar actividades relacionadas con la administración o funcionamiento de la 
entidad. Estos contratos sólo podrán celebrarse con personas naturales cuando dichas actividades no puedan realizarse con personal de planta o requieran conocimientos especializados.

En ningún caso estos contratos generan relación laboral ni prestaciones sociales y se celebrarán por el término estrictamente indispensable”.

La Corte Constitucional, en sentencia C-154 (1997) al estudiar la norma transcrita, determinó, entre otros, las características del contrato de prestación de servicios y sus diferencias con el contrato de trabajo, así: "En síntesis, el elemento de subordinación o dependencia es el que determina la diferencia del contrato laboral frente al de prestación de servicios, ya que en el plano legal debe entenderse que quien celebra un contrato de esta naturaleza, como el previsto en la norma acusada, no puede tener frente a la administración sino la calidad de contratista independiente sin derecho a prestaciones sociales; a contrario sensu, en caso de que se acredite la existencia de un trabajo subordinado o dependiente consistente en la actitud por parte de la administración contratante de impartir órdenes a quien presta el servicio con respecto a la ejecución de la labor contratada, así como la fijación de horario de trabajo para la prestación del servicio, se tipifica el contrato de trabajo con derecho al pago de prestaciones sociales, así se le haya dado la denominación de un contrato de prestación de servicios independiente". Así, cuando el interesado demuestra la subordinación o dependencia respecto del empleador, indefectiblemente en aplicación del principio de prevalencia de la realidad sobre las formas en las relaciones laborales establecidas en el artículo 53 de la Carta Política, se debe declarar la existencia de un contrato laboral, aunque se le hubiere contratado por OPS.

En la sentencia C-614 (2009), a través de la cual estudió la constitucionalidad del inciso final del artículo $2^{\circ}$ del Decreto $2400(1968)^{3}$, la Corte Constitucional ha determinado que "En síntesis, una de las condiciones que permite diferenciar un contrato laboral de un contrato de prestación de servicios es el ejercicio de la labor contratada, pues solo si no hace parte de las funciones propias de la entidad, o haciendo parte de ellas no pueden ejecutarse con empleados de planta o requieran conocimientos especializados, pueden celebrarse contratos de prestación de servicios. De lo contrario, la Administración debe recurrir a la ampliación de la planta de personal para celebrar contratos laborales".

En la sentencia anterior se establecieron los criterios que se sirven para delimitar el campo de la relación laboral y el de la prestación de servicios, a saber:

3 "Para el ejercicio de funciones de carácter permanente se crearán los empleos correspondientes, y en ningún caso, podrán celebrarse contratos de prestación de servicios para el desempeño de tales funciones". 
Luz Karime Agamez Agamez

“i) Criterio funcional: que indica que, si la función contratada está referida a las que usualmente debe adelantar la entidad pública, en los términos señalados en el reglamento, la ley y la Constitución, será de aquellas que debe ejecutarse mediante vínculo labora. ii) Criterio de igualdad: Si las labores desarrolladas son las mismas que las de los servidores públicos vinculados en planta de personal de la entidad y, además se cumplen los tres elementos de la relación laboral, debe acudirse a la relación legal y reglamentaria o al contrato laboral y no a la contratación pública (Consejo de Estado, Sección Segunda, sentencia citada del 6 de septiembre de 2008). iii) Criterio temporal o de la habitualidad: Si las funciones contratadas se asemejan a la constancia o cotidianidad, que conlleva el cumplimiento de un horario de trabajo o la realización frecuente de la labor, surge una relación laboral y no contractual (Consejo de Estado, Sección Segunda, sentencia ya citada del 3 de julio de 2003). iv) Criterio de la excepcionalidad: si la tarea acordada corresponde a "actividades nuevas" y éstas no pueden ser desarrolladas con el personal de planta o se requieren conocimientos especializados o de actividades que, de manera transitoria, resulte necesario redistribuir por excesivo recargo laboral para el personal de planta, puede acudirse a la contratación pública (Consejo de Estado, Sección Segunda, sentencia del 21 de febrero de 2002 a que se ha hecho referencia). Por el contrario, si la gestión contratada equivale al "giro normal de los negocios" de una empresa debe corresponder a una relación laboral y no puramente contractual. v) Criterio de la continuidad: si la vinculación se realizó mediante contratos sucesivos de prestación de servicios, pero para desempeñar funciones del giro ordinario de la Administración, en otras palabras, para desempeñar funciones de carácter permanente, la verdadera relación existente es de tipo laboral. (...)”. (Sentencia C-614 de 2009.)

De lo visto hasta aquí, se resalta que la subordinación a la que está sujeto el trabajador en el contrato de trabajo rige solamente para los efectos propios que se derivan de la relación laboral, es decir, para el cumplimiento de la actividad, servicio, o labor contratada y que, como se expresó permite al empleador dar órdenes, dirigir al trabajador, imponerle reglamentos o sancionarlos disciplinariamente, como desarrollo directo del principio de participación, que también debe estar presente en escenarios tales como los laborales y las relaciones de trabajo. Considerando, que lo propio de todo reglamento de trabajo es el establecimiento de las condiciones de tiempo, modo y lugar en que debe desarrollarse la prestación del servicio, así como las condiciones de seguridad y orden que deben reinar en la empresa, asuntos que son conexos al elemento subordinación. Pero, además, también existen otros aspectos que escapan al ámbito mismo de la subordinación como es la fijación de las escalas de sanciones y faltas, y el procedimiento para formular quejas, cuestiones en las que resulta necesario escuchar la opinión de la otra parte de la relación laboral: los trabajadores. 
Finalmente, en este punto resulta de vital importancia efectuar una diferenciación entre lo que se considera subordinación y las meras actividades de coordinación que pueden surgir entre el contratista y contratante para la realización eficaz del objeto contractual; tal y como lo expresó el Consejo de Estado "Respecto a la subordinación, se ha entendido como la aptitud que tiene el empleador para impartirle órdenes al trabajador y exigirle su cumplimiento, para dirigir su actividad laboral e imponerle los reglamentos internos de trabajo a los cuales debe someterse, "todo dirigido a lograr el objetivo misional trazado". En cuanto a la dirección y coordinación de los contratos de prestación de servicios como modalidad contractual estatal, el artículo 14 de la Ley 80 (1993) establece que la dirección general y la obligación de ejercer control y vigilancia de la ejecución del contrato recaerán en las entidades estatales.

Al respecto, la Sección Segunda ha sostenido que entre contratante y contratista puede existir una relación de coordinación en sus actividades, de manera que el segundo se somete a las condiciones necesarias para el desarrollo eficiente de la actividad encomendada, lo cual puede incluir las siguientes situaciones:

- Un horario.

- El hecho de recibir una serie de instrucciones de sus superiores.

- Tener que reportar informes sobre sus resultados, pero ello no significa necesariamente la configuración de un elemento de subordinación.

De acuerdo con todo lo anterior, el tribunal administrativo enfatizó que la subordinación es determinante para diferenciar el contrato laboral del contrato de prestación de servicios, "puesto que es la mencionada característica la que fija la independencia del contratista de la administración pública y que no genera el derecho a las prestaciones sociales”. (Sentencia 05001233300020130081301, 2016)

Así las cosas, y aunque, de entrada, la fijación de un horario y el hecho de que se impartan ciertas instrucciones pueden ser consideradas como factores configurativos de la subordinación; estas pueden traducirse en una sencilla expresión de la concertación de las partes para llevar a cabo el objeto contractual. Lo anterior indica entonces, que el contratista interesado en probar la existencia de un contrato realidad, debe probar sin que quede duda, la existencia de una subordinación y dependencia a la entidad, tal, que lo ponga en igualdad de condiciones respecto al resto de los servidores.

Los aspectos teóricos, antes expuestos nos muestran que al demostrarse la subordinación se hace necesaria la declaración de un contrato realidad, esto en aplicación del principio de la primacía de la realidad a las relaciones contractuales. 
Luz Karime Agamez Agamez

Para el caso de los trabajadores oficiales, esto se dificulta por cuanto la politización de las estructuras del estado ha aumentado la vinculación a las empresas de este, a través del contrato de prestación de servicios, cuando en realidad se presentan verdaderas relaciones laborales, esto ocurre en la medida en que los CPS permiten al "caudillo" tener un control sobre sus votantes o cumplir compromisos, así pueden cada determinados meses "renovar" y/o finalizar contratos, dependiendo de sus intereses particulares.

Se presenta como punto de discusión la necesidad de establecer una política de contratación real, que obedezca desde el principio a lo que se va a ejecutar, esto por cuanto como se mencionó anteriormente, la vinculación por CPS termina siendo más gravoso para el estado, en la medida en que en los procesos laborales en los que se logra demostrar la subordinación de los que iniciaron como contratistas, siendo realmente trabajadores oficiales (para el caso de estudio), el Estado termina pagando sumas superiores a las que se hubieren cancelado si desde un inicio se hubiera contratado a través de contrato de trabajo.

\section{CONCLUSIONES}

De lo analizado en el presente trabajo se ha establecido principalmente que la subordinación en los contratos laborales de trabajadores oficiales, opera igual que en las otras modalidades de contratación laboral, con la diferencia que en el caso de los trabajadores oficiales el empleador es precisamente el estado; lo que supone desde el punto de vista constitucional una violación sistemática por parte del Estado frente a los derechos de los asociados.

Se establece que la principal diferencia entre un CPS y un contrato de trabajo es la subordinación laboral, lo que supone en últimas que en todo momento se debe tener de presente que, en virtud del principio de primacía de la realidad, el poder de dirección en la actividad laboral y la potestad disciplinaria que se ejerce sobre los trabajadores en una empresa de economía mixta o industrial y comercial del estado, son indicadores del elemento subordinación en la relación laboral. De allí que al planteamiento ¿Qué tan respetados son los derechos de los trabajadores del sector oficial?; encontramos que estos son sistemáticamente violados, en la medida en que no se respetan sus derechos laborales reconocidos en la constitución, tratados internaciones, las leyes y la extensa jurisprudencia nacional.

Se logró establecer que la subordinación en la ejecución de la labor de contratistas del estado que en realidad son trabajadores oficiales, en virtud del principio de primacía de la realidad, opera siempre y cuando los trabajadores logren demostrar a través de un ejercicio probatorio, los elementos que esta supone, y que fueron expuestos en el desarrollo de este trabajo. En verdad, se trata de una temática inacabada si se tiene que a diario la jurisprudencia avanza cada vez más proteccionista a los derechos indiscutibles de los trabajadores oficiales. 


\section{REFENCIAS BIBLIOGRÁFICAS}

Constitución Política de Colombia de 1991. (2017) Legis Editores.

Código Sustantivo del Trabajo y Código Procesal del Trabajo y de la Seguridad Social. (2017) Diario oficial No 27. 622 de 7 de junio de 1951. Legis editores.

Congreso de los Estados Unidos de Colombia. (1873, 31 de mayo) Ley 84 de 1873, Código Civil de los Estados Unidos de Colombia. Diario Oficial No 2.867

Congreso de la República de Colombia. (1945, 14 de marzo). Ley 6 de 1945. Diario oficial $\mathrm{N}^{\mathrm{o}} 25.790$

Congreso de la República de Colombia. (1993, 28 de octubre). Ley 80 de 1993. Diario oficial $\mathrm{N}^{\circ} 41.094$

Consejo de Estado. Sección segunda. Sentencia 05001233300020130081301 (36872014) del 31 de mayo de 2016. [M.P Sandra Lisset Ibarra Vélez del 1 de mayo de 2016]

Corte Constitucional. Sentencia T-161 del 26 de abril de 1993. [M.P Antonio Barrera Carbonel del 266 de abril de 1993]

Corte Constitucional. Sentencia T- 003 del 17 de enero de 1994. [M.P Jorge Arango Mejía del 17 de enero de 1994]

Corte Constitucional. Sentencia C-154 del 19 de marzo de 1997. [M.P Hernando Herrera Vergara del 19 de marzo de 1997]

Corte Constitucional. Sentencia C-614 del 2 de septiembre de 2009. [M.P Jorge Ignacio Pretelt Chaljub del 2 de septiembre de 2009]

Corte Constitucional. Sentencia T-253 del 4 de mayo de 2015. [M.P Gloria Stella Ortiz Delgado del 4 de mayo de 2015]

Corte Constitucional. Sentencia T-426 del 8 de julio de 2015. [M.P Jorge Iván Palacio Palacio del 8 de julio de 2015]

Corte Constitucional. Sentencia T-040 del 22 de enero de 2016. [Eduardo Montealegre Lynett del 22 de enero de 2016] 
Luz Karime Agamez Agamez

Corte Constitucional. Sentencia C-484 del 30 de octubre de 1995. [M.P Fabio Morón Díaz del 330 de octubre de 1995]

Corte Constitucional. Sentencia C-493 del 26 de septiembre de 1996. [M.P Eduardo Cifuentes Muñoz del 26 de septiembre de 1996]

Corte Constitucional. Sentencia C-517 del 10 de agosto de 2017. [M.P Iván Humberto Escruceria Mayolo del 10 de agosto de 2017]

Corte Constitucional. Sentencia C-536 del 16 de octubre de 1996. [M.P Alejandro Martínez Caballero del 16 de octubre de 1996]

Corte Constitucional. Sentencia C-934 del 29 de septiembre de 2004. [M.P Jaime Córdoba Triviño del 29 de septiembre de 2004]

Corte Constitucional. Sentencia C-1110 del 24 de octubre de 2001. [Clara Inés Vargas Hernández Del 24 de octubre de 2001]

Corte Suprema de Justicia. Sala Laboral. Sentencia 25717 del 21 de febrero de 2006. Radicado 25717. [M.P Carlos Isaac Nader del 21 de febrero de 2006]

Corte Suprema de Justicia. Sala Laboral. Sentencia SL11436-2016 del 29 de junio de 2016. [M.P Gerardo Botero Zuluaga del 29 de junio de 2016]

Corte Suprema de Justicia. Sala Laboral. Sentencia SL17363-2017 del 25 de octubre de 2017. [M.P Dolly Amparo Caguasango Villota del 25 de octubre de 2017]

Corte Suprema de Justicia. Sentencia SL 368 del 21 de abril de 1981. [M.P Cesar Ayerbe Chaux del 21 de abril de 1981]

Isaza Cadavid, G. (2012) Derecho Laboral Aplicado. Ediciones Leyer. Bogotá D.C.

Kalach Torres, Gina María (2016). Las comisiones de la verdad en Colombia. Revista Jurídica Mario Alario D'Filippo, Vol 8, número 16: 106-124. DOI: https://doi.org/10.32997/2256-2796-vol.8-num.16-2016-1534

Muñoz Osorio, A. (2012) Aplicación de la primacía de la realidad sobre la formalidad en los contratos de trabajo. Pensamiento americano, Pág. 9-14. 
Presidencia de la República de Colombia. (1971, 16 de junio) Decreto 410 de 1971, Por el cual se expide el Código de Comercio. Diario Oficial N. 33.339

Pérez Huertas, F. (1990) El principio de primacía de la realidad en el contrato individual de trabajo. Universidad Pontifica Javeriana. Bogotá D. C.

Perilla Zamudio, J. F. (2014) Empleados públicos y trabajadores oficiales: un concepto análogo a la luz del ordenamiento legal colombiano vigente. Revista Principia Iuris, Vol. 21. Pág. 197-205. Recuperado de: http://revistas.ustatunja.edu.co/index.php/piuris/article/view/929

Portal Vlex. Diferencia entre empleado público trabajador oficial. Recuperado de: https://vlex.com.co/tags/diferencia-entre-empleado-publico-trabajador-oficial-3509810

Portal Ámbito Jurídico. (29 de julio de 2016). Subordinación, factor determinante del contrato laboral frente a la prestación de servicios: Concejo de Estado. Recuperado de: https://www.ambitojuridico.com/bancoconocimiento/administrativo-ycontratacion/subordinacion-factor-determinante-del-contrato-laboral-frente-al-deprestacion-de-servicios-consejo

Presidencia de la República de Colombia. (1945, 11 de septiembre). Decreto 2127 de 1945. Diario oficial 25.933

Presidencia de la República de Colombia. (1969, 4 de noviembre). Decreto 1848 de 1969. Diario oficial No 32.937

Presidencia de la República de Colombia. (1991, 19 de noviembre). Decreto 2591 de 1991. Diario oficial $\mathrm{N}^{\circ} 40.165$

Presidencia de la República de Colombia. (1968, 18 de octubre). Decreto 2400 de 1968. Diario oficial $\mathrm{N}^{\mathrm{o}} 32.625$

Tirado Pertuz, C. y Luna Salas, F. (2015). La creación pretoriana del Derecho Procesal Constitucional en la Acción de Tutela. Revista Jurídica Mario Alario D’Filippo, Vol. 7, número 14: 22-40. DOI: https://doi.org/10.32997/2256-2796-vol.7-num.14-2015-1515

Viguri Perea, A. y Chiara Marullo, M. (2016) El derecho a un medio ambiente sano y la encrucijada de los alimentos transgénicos. Revista Jurídica Mario Alario D'Filippo, Vol. 8, Número 15: 100-111 DOI: https://doi.org/10.32997/2256-2796-vol.8-num.15-2016-1526 